\title{
CICLO DE VIDA ORGANIZACIONAL: ALINHAMENTO DOS ESTÁGIOS DAS PEQUENAS EMPRESAS EM QUATRO DIMENSÕES
}

\section{ORGANIZATIONAL LIFE CYCLE: ALIGNMENT OF STAGES IN FOUR DIMENSIONS IN SMALL BUSINESS}

\author{
Jair de Oliveira $^{1}$; Edmundo Escrivão Filho ${ }^{2}$ \\ ${ }^{1}$ Universidade Tecnológica Federal do Paraná - UTFPR - Cornélio Procópio - Brasil \\ jair37@gmail.com \\ ${ }^{2}$ Universidade Estadual de São Paulo - USP - São Carlos - Brasil \\ edesfi@sc.usp.br
}

\begin{abstract}
Resumo
O propósito deste trabalho é apresentar uma configuração das especificidades de gestão da pequena empresa em quatro dimensões: Dirigente, Organização, Estratégia e Contexto Organizacional e, a partir dessas dimensões, propor uma categorização do ciclo de vida organizacional. A categorização foi desenvolvida a partir de trabalhos consagrados na literatura internacional. Como resultado, formulou-se um conjunto de categorias, que visam facilitar a identificação do estágio organizacional da pequena empresa do setor metal-mecânico.
\end{abstract}

Palavras-chave: pequena empresa, ciclo de vida organizacional.

\section{Introdução}

As pequenas empresas têm participado ativamente da história da humanidade. Elas surgem com o artesanato e o comércio e sob a influência da Revolução Industrial expandem-se para a manufatura. Atualmente, elas estão presentes em vários setores econômicos, com presença importante no cenário político, econômico e social mundial. De forma que nenhum país em desenvolvimento se consolidaria sem a sua efetiva participação (RAMOS, 1995; JULIEN, 1987).

Dada essa importância, a academia dedica-se a desenvolver teorizações sobre a realidade das pequenas empresas. As primeiras tentativas as trataram como miniaturas das grandes empresas ou como pequenas que ainda não cresceram. As formulações propostas eram mais resultados de ajustes das teorias desenvolvidas para as grandes empresas do que uma teorização especifica e voltada às tipicidades da sua realidade organizacional. O cerne dessas formulações era orientar as pequenas empresas a um crescimento incondicional ou que, pelo menos, morressem tentando alcançá-lo. No entanto, esses conceitos não atenderam satisfatoriamente as demandas teóricas das pequenas. Pois algumas pequenas empresas não comungam o interesse pelo crescimento irrestrito, e a compreensão 
dos seus fenômenos organizacionais é diferente do difundido nas grandes. Verifica-se que uma das interpretações teóricas que contribuem para amenizar essas lacunas e vêm recebendo atenção dos pesquisadores é a teoria do ciclo de vida organizacional (DANDRIDGE, 1979; GALBRAITH, 1982; CHURCHILL; LEWIS, 1983; LEONE, 1999).

Ela identifica e analisa os fenômenos relacionados aos períodos de desenvolvimento das empresas. Esses períodos têm sido postulados como fatores contingênciais importantes para explicação do que ocorre na empresa durante o seu desenvolvimento e na prescrição de medidas gerenciais (KIMBERLY; MILES, 1980; ROBINSON JR. et al., 1984; ADIZES, 1996). Entretanto, o ciclo de vida organizacional é pouco relacionado com outros temas de pesquisas acadêmicas. Um dos principais motivos para esse uso limitado é que, embora ele possua um delineamento teórico consolidado, os critérios para a sua operacionalização ainda carecem de uma sistematização.

Assim, para melhor aplicação da teoria do ciclo de vida organizacional nos estudos sobre a pequena empresa, propõe-se um modelo de categorização dessas empresas por estágio. Elaborada a partir das suas especificidades de gestão, que foram decompostas em quatro dimensões: Dirigente, Organização, Estratégia e Contexto Organizacional. Deste modo, o objetivo deste artigo é construir uma categorização para identificar em qual estágio do ciclo de vida organizacional a pequena empresa se encontra. Para isso, estruturou-se este artigo em cinco seções. Esta seção trata da introdução; a próxima, do marco teórico; a terceira, da proposta de categorização; a quarta, dos resultados; e finalizando, as conclusões.

\section{Marco Teórico}

Para elaborar a categorização proposta neste artigo, procedeu-se a um exame na literatura sobre o tema pequena empresa, examinado a seguir. Após, examinaram-se as especificidades de gestão da pequena empresa e, por fim, o ciclo de vida organizacional.

\subsection{Pequena Empresa}

A literatura mostra que várias mudanças no comportamento organizacional são vinculadas ao tamanho da empresa (DANDRIDGE, 1979; KIMBERLY; MILES, 1980; ROBINSON JR. et al., 1984; ADIZES, 1996 LEONE, 1999). Empresas com tamanhos diferentes apresentam problemas diferentes, que demandam soluções diferentes (LEONE, 1991). Na pequena empresa o dirigente conhece e mantém contato pessoal, quase que diário, com todos os funcionários. Enquanto que na grande o presidente sabe onde estão e quantos são os seus colaboradores, mas não mantém contato direto com eles (DRUCKER, 1981). Esses casos são pequenos exemplos das particularidades 
inerentes aos portes das empresas; por isso, a definição do tamanho das empresas é um assunto recorrente na literatura administrativa e econômica.

Essa questão interessa tanto aos acadêmicos, que precisam criar categorias de análises, como aos governantes, que necessitam formular políticas de incentivos e de proteção relacionadas aos diferentes portes de empresas (DRUCKER, 1981). Nas últimas décadas, várias medidas foram sugeridas para se definir os portes das empresas; entretanto, elas ainda não conseguiram unanimidade entre a comunidade acadêmica (TORRÈS; JULIEN, 2005). Existem muitas definições possíveis, as quais divergem entre os autores, entre países e entre os órgãos oficiais de um mesmo país (D'AMBOISE; MULDOWNEY, 1988; RAMOS, 1995; JULIEN, 1997). Assim, embora não haja consenso sobre os critérios para definição dos portes das empresas, é preciso distinguir o que seja uma pequena empresa, antes de se teorizar sobre elas.

O que se pode fazer para esse intuito é utilizar alguns parâmetros de ordem quantitativa. Os mais utilizados são o número de empregados por setor econômico, o montante de faturamento, o volume de vendas por períodos e o capital social (D'AMBOISE; MULDOWNEY, 1988; LEONE, 1991). Porém, em determinadas situações esses critérios não traduzem a realidade das pequenas empresas. Uma vez que eles apuraram apenas elementos superficiais da empresa e não capturam os aspectos dos comportamentos internos e das relações com os demais integrantes do setor. Ao se considerar apenas esses critérios, uma empresa pode ser rotulada como pequena, mas quando analisada sob outro prisma, pertencer a outro porte. Situação que desvirtuaria a definição precisa do porte das empresas e, consequentemente, a análise dos resultados nos estudos sobre elas (RATTNER et al., 1985; DRUCKER, 1981).

A fim de amenizar essas contradições, cresce entre os autores a aceitação do uso de critérios de ordem qualitativa. Entre os critérios qualitativos mencionados na literatura, destacam-se os seguintes: o tipo de propriedade, o tipo de vínculo entre a família e a empresa, o grau de dependência em relação a outras empresas, o nível de centralização das decisões e o tipo de estrutura organizacional (DRUCKER, 1981; RAMOS, 1995). Desses critérios, um dos principais é o tipo de estrutura, pois ela espelharia o tamanho da empresa. Segundo Drucker (1981), existe uma forte relação entre o seu porte e o tipo de estrutura requerida. Mesmo com essa lista de opções e sendo a adoção de critérios qualitativos analiticamente interessantes, eles não são usados com muita frequência, dada a sua dificuldade de tratamento, principalmente, quando a amostra envolve um grande número de empresas (JULIEN, 1997, LEONE, 1991; TORRÈS; JULIEN, 2005).

Se os critérios quantitativos não traduzem o que é uma pequena e os qualitativos são difíceis de operacionalizar, a solução para esse dilema passaria pela combinação de ambos, embora essa tratativa não seja comum. A partir disso, observa-se que os critérios quantitativos são usados em alguns estudos como ponto de partida e os qualitativos como suporte para distinguir na população 
de empresas quais seriam as pequenas que comporiam a amostra final. Contudo, esse progresso ainda não soluciona toda a problemática. Porque uma grande empresa poderia conservar várias práticas e características do seu período de pequena (TORRÈS; JULIEN, 2005). Por isso, alguns pesquisadores, como Torrès e Julien (2005), discutem, em uma linha de pesquisa incipiente, a definição de outros critérios de classificação fundamentados por um referencial contingencial. O qual consiste na tese de que as especificidades da pequena empresa são sujeitas a certas condições, mas fora desse limite a tese escolhida é irrelevante.

Para trazer algum alento aos pesquisadores, há um entendimento sobre a definição de pequena empresa - de que estas poderiam ser todas as empresas que não são grandes. Segundo esse entendimento, pequena empresa englobaria o que os órgãos oficiais do Brasil classificam de micro, pequena e média. Isso é, na verdade, mais um apelo para voltar a atenção e destinar apoio para as empresas do que uma proposta de classificação.

Assim, como a discussão sobre este assunto encontra-se em aberto, adotam-se neste trabalho as propostas do SEBRAE (2006) e do Small Business Administration (SBA, 2008), para definir o que é uma pequena empresa. Elas classificam o tamanho das empresas de acordo com o número de funcionários, considerando o setor econômico de atuação e a independência quanto a grandes empresas. Portanto, define-se como pequena empresa do setor metal-mecânico aquela com até 500 empregados. Quanto ao número mínimo de empregados, embora não considerado neste trabalho, precisa ser avaliado nos estudos sobre pequena empresa, pois empresas com poucos empregados ou com empregados familiares podem distorcer os resultados das análises.

\subsubsection{Especificidades de Gestão da Pequena Empresa}

Embora a classificação de pequena empresa pelo número de funcionários não seja a ideal, ela pelo menos permite começar a discussão sobre as características que tornam as pequenas empresas diferentes das grandes. Essas diferenças abrangem todas as esferas de atuação das pequenas, desde a área operacional até a estratégica. Particularmente, este trabalho interessa pelas características da esfera relacionada à direção, as quais são denominadas aqui como especificidades de gestão da pequena empresa. Para retratar essas especificidades, foi proposto o uso de uma tipologia com quatro dimensões.

Hall (1984) defende a formulação de tipologias, para determinar quais são as variáveis organizacionais a serem investigadas, pois os padrões de comportamentos organizacionais podem ser descritos em forma de modelos analíticos e interpretativos. Embora, para isso, existam dificuldades, a teoria administrativa precisa modelar o comportamento e as influências das relações organizacionais complexas, a fim de que se possa contribuir mais eficientemente com a 
função de teorizar, de projetar, de construir e de operar as organizações (HALL, 1984; NADLER et al., 1994).

A tipologia aqui proposta foi elaborada a partir dos trabalhos teóricos de Gartner (1985), Nadler et al. (1994) e Leone (1999) e do trabalho empírico de Terence (2008). Os delineamentos de Gatner (1985) e Leone (1999) são específicos à pequena empresa, enquanto o de Nadler et al. (1994) é de âmbito geral. Recorreu-se a esses autores porque Gartner (1985) dedicou especial atenção em desenvolver suposições das relações causais entre as variáveis pertencentes às dimensões indivíduo, ambiente organizacional, processo e organização. A Leone (1999), porque ela sintetizou as especificidades da pequena empresa em três vias: organizacional, decisional e individual. A Nadler et al. (1994) porque, embora a sua tipologia não trate especificamente da pequena empresa, ela possui uma boa aceitação na academia e mostra-se útil quando associada à realidade das empresas desse porte (ESCRIVÃO FILHO et al. 2005). A Terence (2008), porque ela expôs os esforços contínuos dos integrantes do grupo de pesquisa de Estudos Organizacionais da Pequena Empresa - GEOPE em identificar, aperfeiçoar e representar a realidade organizacional das pequenas empresas por meio de uma tipologia.

Terence (2008) representa as características das pequenas empresas em quatro dimensões, expressas triangularmente, conforme figura 1. Os vértices da figura representam as dimensões: dirigente, organização e contexto organizacional e, no centro do triângulo é posicionado a estratégia. Assim, considerando-se a necessidade de examinar as pequenas empresas sob a perspectiva do seu processo de nascimento, crescimento, plenitude e declínio (GREINER, 1972; 1998; KIMBERLY; MILES, 1980; ADIZES, 1996), utiliza-se a tipologia sugerida por Terence (2008).

Figura 1 - Dimensões de Especificidades de Gestão da Pequena Empresa

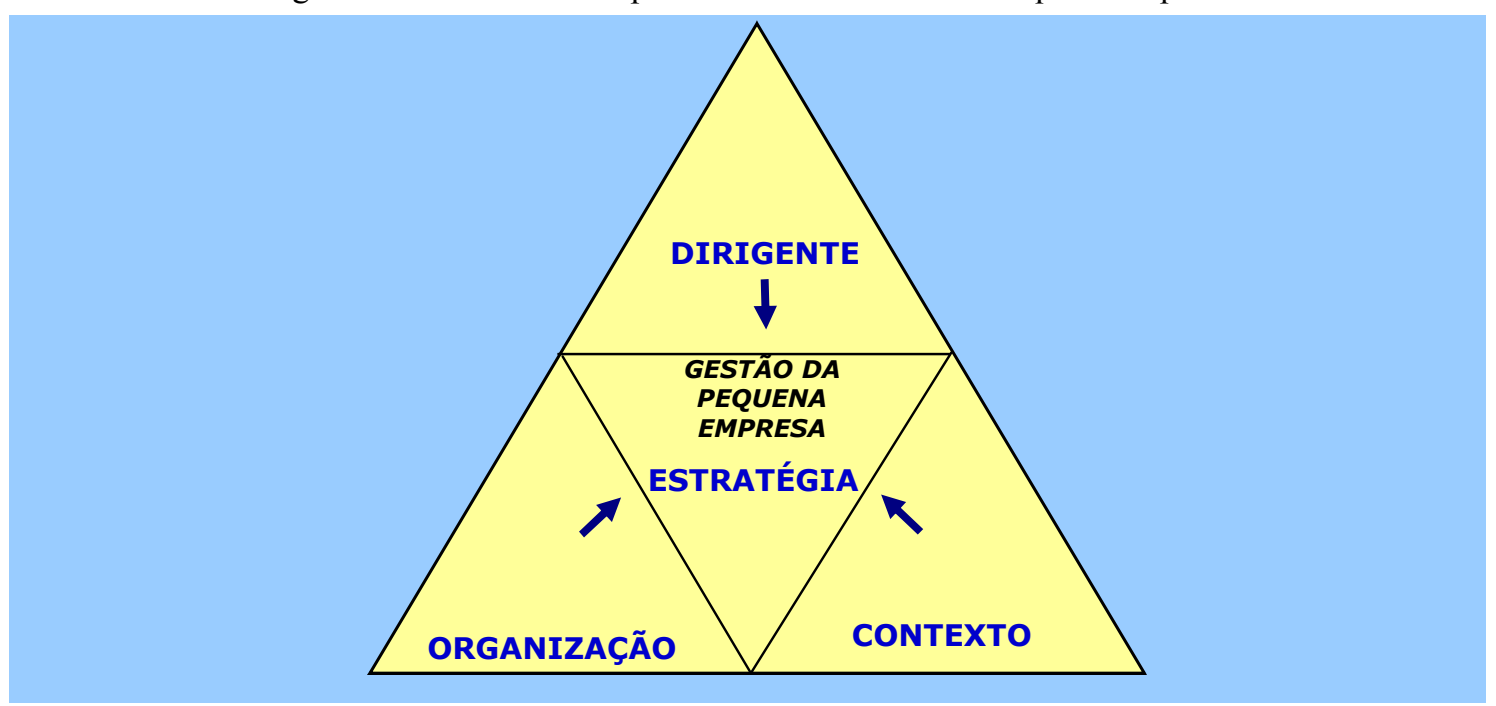

Fonte: Adaptado de Terence (2008) 
Esta tipologia demonstrar a possibilidade de se caracterizar a pequena empresa a partir de quatro dimensões inter-relacionadas: dirigente, organização, estratégia e contexto organizacional, as quais influenciam diretamente na gestão da pequena empresa.

Observar-se na pequena empresa a existência de um contínuo, no grau de formalização dos seus processos e da sua estrutura (SCHEIN, 1980). Esse prolongamento mostra que conforme a pequena empresa se desenvolve, ela muda o modo de lidar com as suas demandas. Assim, quanto mais desenvolvida, mais ela tenderá a formalizar-se e a distanciar-se da simbiose empresa e família (SCHEIN, 1980; LEONE, 1999). Uma das teorias que compreendem os aspectos inerentes a este fenômeno é a teoria do ciclo de vida organizacional, examinada a seguir.

\subsection{Ciclo de Vida Organizacional}

Para vários autores, as empresas ao longo do seu período de desenvolvimento passam por períodos previsíveis, e em cada período, apresentam características similares, principalmente quanto às suas estratégias, estruturas e processos. Esta área de estudo é denominada de Ciclo de Vida Organizacional (GREINER, 1972; KYMBERLY; MILES, 1980; CHURCHILL; LEWIS, 1983; SCOTT; BRUCE, 1987; O'RAND; KRECKER, 1990; DODGE; FULLERTON; ROBBINS, 1994; ADIZES, 1996).

A teoria do ciclo de vida organizacional analisa os fenômenos relacionados às mudanças das características das organizações ao longo do tempo e das suas capacidades de adaptação ao ambiente (GUPTA; CHIN, 1994; O'RAND; KRECHER, 1990). Considerada uma metáfora, assim de forma parcial, é uma opção teórica profícua para se realizar analogias sobre os aspectos do desenvolvimento das empresas durante os períodos de sua existência (O'RAND; KRECHER, 1990; ADIZES, 1996; KIMBERLY, 1980a), pois adota o pressuposto de que as empresas durante a sua existência passam por estágios, e em cada um, apresentam um conjunto de similaridades e de demandas iguais.

Os modelos de ciclo de vida organizacional divergem-se quanto às denominações das fases, das unidades de análises, do número de estágios e da inclusão ou não de um estágio de préconcepção ou de um estágio de declínio ao modelo. A quantidade de estágio altera-se entre os autores: de três estágios (COOPER, 1979; MACHADO-DA-SILVA, VIEIRA e DELLAGNELO, 1998) a dez estágios (ADIZES, 1996). Galbraith (1982) e Adizes (1996) incluíram um estágio inicial, e Miller e Friensen (1984) e Adizes (1996), um estágio sobre a fase de declínio. Para Churchill e Lewis (1983) o declínio é uma das opções disponíveis na fase de maturidade, enquanto Greiner (1972) considera que o estágio de declínio depende das respostas das organizações aos problemas inerentes aos estágios. Para Hanks et al. (1993) duas condições explicariam a ausência 
do estágio de declínio em alguns modelos: primeiro, é que as implicações do declínio na estrutura e nos sistemas são menos previsíveis do que quando associados com o crescimento da empresa; segundo: é porque o declínio, eventualmente, pode ocorrer a partir de qualquer estágio.

Os modelos de ciclo de vida organizacional divergem também quanto à ênfase ao porte de empresa. Existem modelos voltados para as grandes empresas, modelos direcionados para as pequenas e modelos genéricos. A seguir, apresentam-se modelos voltados à pequena empresa.

\subsubsection{Modelos de Ciclo de Vida Organizacional para Pequena Empresa}

Entre os modelos de ciclo de vida organizacional tratados nesta seção está o de Greiner de 1972, republicado em 1998; o de Galbraith (1982); o de Churchill e Lewis (1983); o de Scott e Bruce (1987); Hanks et al. (1993); e um recente trabalho de Lester et al. (2003).

O modelo de Greiner $(1972 ; 1998)$ é composto de cinco estágios e é direcionado às empresas do setor industrial, com crescimento moderado. Greiner (1972) elaborou o seu modelo considerando o tamanho e a idade da empresa. Para ele, conforme a empresa amadurece e o seu tamanho aumenta, ela muda de estágio e os seus problemas ficam mais evidentes, até atingir um momento de crise, no qual as técnicas e os métodos até então empregados não são tão eficazes. Para definir os conteúdos dos estágios ele considerou cinco situações da empresa: o tempo de vida, o tamanho, o estágio de evolução, o estágio de revolução e a taxa de crescimento na indústria.

Os cinco estágios do modelo de Greiner (1972) são: criatividade, direção, delegação, coordenação e colaboração. Esses estágios congregam uma provável sequência estável de desenvolvimento, denominado de processo de evolução. Entretanto, conforme as empresas se desenvolvem enfrentam momentos turbulentos ou situações de crises, os quais são considerados pelo autor como os propulsores de mudanças de estágio. Essas situações turbulentas são os momentos de revolução. Assim, o modelo de Greiner (1972) preconiza a existência de uma sequência composta por um estágio de evolução, seguindo por um período de revolução.

O modelo de Churchill e Lewis (1983), composto também por cinco estágios, é embasado pela combinação das experiências dos autores, com um levantamento na literatura e com a realização de uma pesquisa empírica. Churchill e Lewis (1983) categorizam os problemas e os padrões de crescimento das pequenas empresas, a partir da identificação de fatores gerenciais, do tamanho, da diversidade e da complexidade da empresa. Os autores denominaram os cinco estágios como: existência, sobrevivência, sucesso, decolagem e maturidade.

A proposta de Scott e Bruce (1987) é baseada em cinco estágios, os quais são denominados de concepção, sobrevivência, crescimento, expansão e maturidade. Na formulação do modelo, os autores introduziram uma proposta de crescimento curvilíneo em resposta ao modelo linear de 
Greiner (1972). Eles mantiveram os períodos de crises que precedem cada estágio, sugeridos por Greiner (1972), e avaliaram que a velocidade e o tempo de desenvolvimento divergem entre as empresas. Na definição das variáveis, eles utilizaram o tempo de vida dos produtos da empresa, o tamanho e a idade do negócio, analisados sob cinco conjuntos de variáveis: ambiente, estratégia, dirigente, operacional e organização.

O modelo de Hanks et al. (1993) com quatro estágios é voltado para as empresa do setor de alta tecnologia. Os autores destinaram mais atenção na definição de critérios concretos de classificação das empresas nos respectivos estágios. Desta forma, além de um modelo de ciclo de vida, eles também apresentaram um método para classificação das empresas fundamentado em variáveis relacionadas ao contexto organizacional e à estrutura organizacional. Os estágios propostos pelos autores são: constituição, expansão, maturidade e diversidade ou declínio.

Lester et al.(2003) propuseram um modelo de cinco estágios e construíram, por meio de um estudo empírico, uma escala para classificação individual das empresas nos respectivos estágios. O modelo é genérico e elaborado a partir de propostas disponíveis na literatura. Por isso, mantém similaridades com os modelos de Churchill e Lewis (1983) e Quinn e Cameron (1983). Os cincos estágios do modelo são: existência, sobrevivência, sucesso, renovação e declínio. Quanto à escala, ela é um reforço expressivo para o estudo do ciclo de vida das organizações e um instrumento de diagnóstico gerencial. No entanto, como ela abrange vários portes de empresas, pode produzir resultados divergentes, quando direcionada para pequenas empresas.

Esses modelos, embora mantenham similaridades quanto à quantidade de estágios, apresentam diferenças quanto aos rótulos dos estágios e quanto às descrições das características dos estágios. Por isso, sugere-se dispor os diversos estágios dos modelos em colunas afins, disposição que denominamos de arranjo. Para compor o arranjo, seguiram-se três etapas. Na primeira, compararam-se os conteúdos dos três primeiros estágios dos modelos de Greiner (1972) com os de Churchill e Lewis (1983), a partir das descrições constantes nos trabalhos de Escrivão Filho (2006) e Oliveira e Silva (2007). Em seguida, estabeleceu-se, entre os pares de estágios, uma síntese. Apurou-se que, no primeiro estágio, a pequena empresa procura estabelecer-se no mercado. No segundo, criar um senso de direção para orientar a sua sobrevivência e, no estágio três, consolidarse e pensar em seu crescimento, conforme quadro 1.

Quadro 1 - Características principais dos estágios do Ciclo de Vida Organizacional

\begin{tabular}{|c|c|c|c|c|}
\hline & GREINER (1992) & CHURCHILL e LEWIS (1983) & SÍNTESE \\
\hline \multirow{3}{*}{ 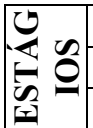 } & 1 & CRIATIVIDADE & EXISTÊNCIA & Estabelecer-se no mercado \\
\hline & 2 & DIREÇÃO & SOBREVIVÊNCIA & Criar um senso de direção para sobreviver \\
\hline & 3 & DELEGAÇÃO & SUCESSO & Consolidar a empresa e pensar no crescimento \\
\hline
\end{tabular}

Fonte: Adaptado de Escrivão Filho (2006) e Oliveira e Silva (2007) 
$\mathrm{Na}$ etapa dois, analisaram-se os arranjos apresentados nos trabalho de Quinn e Cameron (1983) e de Hanks et al. (1993), e procurou-se diminuir as divergências entre eles também com a síntese constante do quadro 1. A principal divergência encontrada no modelo de Quinn e Cameron (1983) com a síntese do quadro 1 foi quanto ao agrupamento dos estágios. Pois os autores agruparam os estágios delegação, coordenação e colaboração de Greiner (1972) sob um mesmo rótulo, denominado como estruturação. Enquanto que o arranjo de Hanks et al. (1993), por sua vez, agrupa os dois primeiros estágios de Churchill e Lewis (1983) sob um mesmo estágio, denominado de Start-up. Após essas análises e considerações, na última etapa para construção do arranjo, finalizou-se a proposta, estabelecendo conexões entre as sínteses do quadro 1 com os modelos de Galbraith (1982), Scott e Bruce (1987) e Lester et al. (2003).

Como resultado, apresenta-se um arranjo com seis estágios retratados, no quadro 2. Ressaltese que o arranjo proposto possui limitações - ele é uma tentativa de sistematizar os modelos de ciclo de vida e minimizar as diferenças existentes entre eles. Pois sabe-se que a compatibilidade entre os modelos é apenas relativa, dado os critérios escolhidos pelos autores para a caracterização dos estágios serem bastante diversos entre si (MACHADO-DA-SILVA, VIEIRA; DELLAGNELO, 1998).

Quadro 2 - Síntese dos estágios dos modelos de Ciclo de Vida Organizacional

\begin{tabular}{|l|c|c|c|c|c|c|}
\cline { 2 - 7 } \multicolumn{1}{c|}{} & \multicolumn{9}{c|}{ Eutor } & Inicial & $\mathbf{1}$ & $\mathbf{2}$ & $\mathbf{3}$ & $\mathbf{4}$ & $\mathbf{5}$ \\
\hline Greiner (1972) & - & Criatividade & Direção & Delegação & Coordenação & Colaboração \\
\hline Galbraith (1982) & $\begin{array}{r}\text { Prova } \\
\text { inicial } \\
\text { - protótipo }\end{array}$ & $\begin{array}{r}\text { Loja modelo } \\
\text { - }\end{array}$ & $\begin{array}{c}\text { Volume de } \\
\text { produção }\end{array}$ & $\begin{array}{c}\text { Crescimento } \\
\text { natural }\end{array}$ & $\begin{array}{c}\text { Manobra } \\
\text { estratégica }\end{array}$ & - \\
\hline Churchill e Lewis (1983) & --- & Existência & $\begin{array}{c}\text { Sobrevivênci } \\
\text { a }\end{array}$ & Sucesso & Decolagem & Maturidade \\
\hline Scott e Bruce (1987) & $\begin{array}{c}\text { Concepçã } \\
\text { o }\end{array}$ & $\begin{array}{c}\text { Sobrevivênci } \\
\text { a }\end{array}$ & $\begin{array}{c}\text { Crescimento } \\
\text { Expansão }\end{array}$ & Maturidade \\
\hline Hanks et al. (1993) & \multicolumn{2}{|c|}{ Star-up } & Expansão & Maturidade & $\begin{array}{c}\text { Diversificaçã } \\
\text { o }\end{array}$ \\
\hline Lester et al. (2003) & - & $\begin{array}{c}\text { Sobrevivênci } \\
\text { a }\end{array}$ & Sucesso & Renovação & Declínio \\
\hline
\end{tabular}

Fonte: Elaborado pelos autores (2009).

Embora o arranjo mostre seis estágios, foram selecionados para a categorização proposta neste trabalho apenas três, pois considerou-se que o estágio inicial refere-se ao período antes do início da empresa - conceituado como período de namoro por Adizes (1996), no qual se estuda a idéia de constituição da empresa (ADIZES, 1996). Neste estágio inicial, constam a fase de concepção sugerida por Scott e Bruce (1987) e algumas tarefas do estágio-prova inicial do modelo de Galbraith (1982), que versa sobre a invenção do produto e a disposição do empreendedor para 
correr riscos. Além disso, fixaram-se três estágios, porque, a partir do quarto estágio ou as descrições das características dos estágios são muito destoantes entre si ou elas são mais próximas à realidade das grandes empresas. Assim, definiram-se os estágios 1, 2, e 3 para compor a categorização, que são examinados na sequência.

\section{Categorização do Ciclo de Vida Organizacional na Pequena Empresa}

Esta seção trata da conciliação dos principais modelos de ciclo de vida organizacional orientados à pequena empresa, considerando as dimensões: Dirigente, Organização, Estratégia e Contexto Organizacional. Trata também, ao final, do agrupamento das variáveis dessas dimensões em dois três estágios, identificados na seção anterior.

\subsection{Conciliação dos modelos de Ciclo de Vida Organizacional}

Dada a diversidade de critérios utilizados para identificar e posteriormente rotular as empresas em determinados estágios do ciclo de vida organizacional, apresenta-se uma conciliação desses critérios. Para realizá-la, primeiramente, levantaram-se os principais critérios constantes nos trabalhos de Greiner (1972), Galbraith (1982), Churchill e Lewis (1983), Scott e Bruce (1987), Hanks et al. (1993) e Lester, et al. (2003). Após, esses critérios foram distribuídos em uma das seguintes dimensões: Dirigente, Organização, Estratégia e Contexto Organizacional, considerandose o grau de afinidade. Como resultado, apresenta-se quatro conjuntos de critérios, dispostos em um das colunas dos quadros $3,4,5$ e 6 , correspondendo às respectivas dimensões, que são detalhadas a seguir.

\subsection{Dirigente}

Esta dimensão ilustra o comportamento dos dirigentes da pequena empresa nos três primeiros estágios. Em um primeiro momento, ele foi considerado como um piloto de uma aeronave, cuja incumbência central é seguir a rota de crescimento (GREINER, 1972). Posteriormente, Galbraith (1982) tratou como um moldador ou um combinador das principais peças da organização, conforme as tarefas as serem executas o exigem. Para Churchill e Lewis (1983), a figura do dirigente se confunde com a da própria empresa. Ele age como um músico, que domina bem um instrumento e que se torna maestro; no entanto, às vezes, por se sentir inconformado ou desiludido, ele acaba por retornar à função de músico.

Quadro 3 - Descrição das categorias da dimensão dirigentes

\begin{tabular}{|l|c|c|c|c|}
\hline \multicolumn{5}{|c|}{ DIRIGENTE } \\
\hline Autor & Critérios & Estágio 1 & Estágio 2 & Estágio 3 \\
\hline
\end{tabular}




\begin{tabular}{|c|c|c|c|c|}
\hline \multirow{3}{*}{$\begin{array}{l}\text { Greiner } \\
(1972)\end{array}$} & $\begin{array}{l}\text { Atividades dos } \\
\text { empreendedores }\end{array}$ & $\begin{array}{l}\text { - Operacional, } \\
\text { produção e vendas }\end{array}$ & $\begin{array}{l}\text { - Organizar a } \\
\text { empresa com novos } \\
\text { contratados }\end{array}$ & $\begin{array}{l}\text { - Gerencia por } \\
\text { relatórios }\end{array}$ \\
\hline & Estilo gerencial & $\begin{array}{l}\text { - Individualismos e } \\
\text { Empreendedor }\end{array}$ & - Diretivo & - Delegar \\
\hline & Sistema de recompensa & - Propriedade & - Salários e mérito & - Bônus individual \\
\hline $\begin{array}{c}\text { Galbraith } \\
(1982)\end{array}$ & Modelo de líder & $\begin{array}{l}\text { - Comandante/ } \\
\text { - Treinador } \\
\end{array}$ & - Treinador & - Gerente \\
\hline \multirow{3}{*}{$\begin{array}{l}\text { Churchill e } \\
\text { Lewis (1983) }\end{array}$} & Atividades do proprietário & $\begin{array}{l}\text { - Executa todas as } \\
\text { tarefas importantes. } \\
\text { - Foco operacional }\end{array}$ & $\begin{array}{l}\text { - Toma todas as } \\
\text { decisões } \\
\text { importantes. } \\
\text { - Foco gerencial }\end{array}$ & $\begin{array}{r}\text { - Orientar e } \\
\text { Gerenciar }\end{array}$ \\
\hline & Estilo de gerenciamento & - Supervisão direta & • Supervisão & - Funcional \\
\hline & $\begin{array}{l}\text { Envolvimento do } \\
\text { empreendedor na empresa }\end{array}$ & - Médio & - Alto & - Regular \\
\hline \multirow{2}{*}{$\begin{array}{l}\text { Scott e Bruce } \\
\quad(1987)\end{array}$} & $\begin{array}{l}\text { Papel do dirigente } \\
\text { principal }\end{array}$ & - Supervisão direta & $\begin{array}{l}\text { - Supervisão } \\
\text { supervisionada }\end{array}$ & $\begin{array}{l}\text { - Delegação } \\
\text { coordenação } \\
\end{array}$ \\
\hline & Estilo gerencial & $\begin{array}{l}\text { - Empreendedor } \\
\text { individual }\end{array}$ & $\begin{array}{l}\text { - Empreendedor, } \\
\text { administrativo }\end{array}$ & $\begin{array}{l}\text { - Empreendedor, } \\
\text { coordenador }\end{array}$ \\
\hline $\begin{array}{l}\text { Hanks et al. } \\
\text { (1993) }\end{array}$ & - & - & - & - \\
\hline $\begin{array}{l}\text { Lester et al. } \\
\text { (2003) }\end{array}$ & Estilo de decisão & $\begin{array}{l}\text { - Centralizado } \\
\text { - Tentativa e erro }\end{array}$ & $\begin{array}{l}\text { - Alguma delegação } \\
\text { - Alguma } \\
\text { formalização }\end{array}$ & $\begin{array}{l}\text { - Confiança } \\
\text { - Uso de sistema de } \\
\text { informação }\end{array}$ \\
\hline
\end{tabular}

Fonte: Elaborado pelos autores (2009).

No primeiro estágio, conforme apresentado no quadro 3 , o dirigente dedica a maior parte do seu tempo à execução de atividades operacionais. Nesse período, a supervisão é direta, e a tomada de decisão é centralizada e por tentativa e erro. O estilo gerencial é empreendedor-individual. O tipo comandante/treinador, sugerido por Galbraith (1982), destoa levemente dos demais autores, pois foi concebido para empresas de base tecnológica, nas quais a incumbência do dirigente é conduzir e mobilizar a empresa para o desenvolvimento e para a comercialização de produtos inovadores (GREINER, 1972; GALBRAITH, 1982; CHURCHILL; LEWIS, 1983; SCOTT; BRUCE, 1987; LESTER et al., 2003).

Do estágio um para o estágio dois, as mudanças observadas nas ações dos dirigentes são expressivas. Nas empresas voltadas para manufatura e tecnologia, o perfil passa de amador, na área administrativa e de comercialização, para um tipo semi-profissional. A empresa contrata novos gerentes e prevalece a supervisão indireta (GREINER, 1972; CHURCHILL; LEWIS, 1983; SCOTT; BRUCE, 1987). Apesar de delegar algumas funções aos novos contratados, ainda sobressai o estilo empreendedor do dirigente. Ele ainda decide sozinho sobre questões importantes. Greiner (1972) descreveu esse estilo como diretivo, e Galbraith (1982), que no estágio anterior o qualificou como comandante/treinador, agora define o dirigente somente como treinador.

No terceiro estágio, o trabalho do dirigente na pequena empresa é influenciado pelas confluências das dimensões organização e estratégia. A estratégia escolhida, a estruturação da empresa e a implementação de sistemas e processos de suporte e controle conduzem a um estilo 
profissional gerencial e à principal característica do dirigente de delegação-coordenação (CHURCHILL; LEWIS, 1983; SCOTT; BRUCE, 1987). As atividades dos dirigentes são apoiadas pelo uso de sistemas de informação e processos de comunicação formalizados. O estilo do dirigente muda de empreendedor para coordenador, e a importância da sua presença para a empresa diminui gradativamente (CHURCHILL; LEWIS, 1983; SCOTT; BRUCE, 1987).

\subsection{Organização}

Os pesquisadores sobre ciclo de vida organizacional utilizaram diferentes terminologias para rotular as categorias das variáveis desta dimensão. Por isso, baseado nos comentários de Machadoda-Silva, Vieira e Dellagnelo (1998), os conteúdos semelhantes foram reunidos em quatro grupos: formalização, estrutura, descentralização e informações gerais, conforme apresentado no quadro 4.

No primeiro grupo, constam as categorias sobre como a formalização se desenvolve na empresa e as características que ela abrange. Greiner (1972) intitulou de grau de formalização na comunicação;, Galbraith (1982), de processos; Churchill e Lewis (1983), de extensão dos sistemas formais; e Hanks et al. (1993), de formalização. O processo para Galbraith (1982) engloba as definições dos sistemas de comunicação e informação, dos orçamentos, dos sistemas de planejamento e dos tipos de controles e critérios de mensuração. Quando Galbraith (1982) definiu as condições do processo, ele considerou o nível de formalização adotado pela empresa; por isso, essa categoria foi incluída no grupo formalização.

Quadro 4 - Descrição das categorias da dimensão organização

\begin{tabular}{|c|c|c|c|c|c|}
\hline \multicolumn{6}{|c|}{ ORGANIZAÇÃO } \\
\hline Grupos & Critérios & Autor & Estágio 1 & Estágio 2 & Estágio 3 \\
\hline \multirow{4}{*}{ 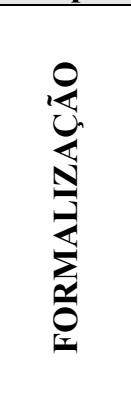 } & Comunicação & $\begin{array}{l}\text { Greiner } \\
(1972)\end{array}$ & Informal & $\begin{array}{l}\text { Mais formal e } \\
\text { impessoal }\end{array}$ & Formal \\
\hline & Processos & $\begin{array}{l}\text { Galbraith } \\
\text { (1982) }\end{array}$ & $\begin{array}{l}\text { Informal } \\
\text { e pessoal }\end{array}$ & $\begin{array}{c}\text { Formal; sistemas e } \\
\text { procedimentos }\end{array}$ & Controle formal \\
\hline & $\begin{array}{l}\text { Extensão do } \\
\text { sistemas } \\
\text { Formais } \\
\end{array}$ & $\begin{array}{c}\text { Churchill } \\
\text { e Lewis } \\
\text { (1983) } \\
\end{array}$ & $\begin{array}{l}\text { Mínimo ou não } \\
\text { existente }\end{array}$ & Mínimo & Básico \\
\hline & Formalização & $\begin{array}{l}\text { Hanks et } \\
\text { al. (1993) }\end{array}$ & $\begin{array}{l}\text { Muito informal; } \\
\text { pessoal e flexível }\end{array}$ & $\begin{array}{c}\text { Começa a emergir } \\
\text { um sistema formal, } \\
\text { mas fraco. }\end{array}$ & Formal burocrático. \\
\hline \multirow{4}{*}{ 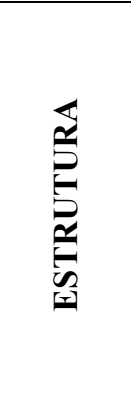 } & Estrutura & $\begin{array}{l}\text { Greiner } \\
\text { (1972) }\end{array}$ & Informal & $\begin{array}{l}\text { Centralizada e } \\
\text { funcional }\end{array}$ & $\begin{array}{l}\text { Descentralizada e } \\
\text { geográfica }\end{array}$ \\
\hline & Estrutura & $\begin{array}{c}\text { Galbraith } \\
\text { (1982) }\end{array}$ & Informal & Funcional & Funcional com ligações \\
\hline & Organização & $\begin{array}{c}\text { Churchill } \\
\text { e Lewis } \\
\text { (1983) }\end{array}$ & Simples & $\begin{array}{l}\text { Simples mas com } \\
\text { um nível }\end{array}$ & Estrutura Funcional \\
\hline & Estrutura & $\begin{array}{l}\text { Scott e } \\
\text { Bruce } \\
(1987)\end{array}$ & Desestruturada & Simples & Funcional, centralizada \\
\hline
\end{tabular}




\begin{tabular}{|c|c|c|c|c|c|}
\hline & Estrutura & $\begin{array}{l}\text { Hanks et } \\
\text { al. (1993) }\end{array}$ & Simples & Funcional & Divisional \\
\hline & Estrutura & $\begin{array}{l}\text { Lester et } \\
\text { al. (2003) }\end{array}$ & Informal e simples & $\begin{array}{l}\text { Funcional. Alguma } \\
\text { formalidade }\end{array}$ & $\begin{array}{c}\text { Funcional, formal e } \\
\text { burocrático }\end{array}$ \\
\hline \multirow{2}{*}{ 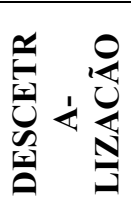 } & $\begin{array}{l}\text { Grau de } \\
\text { centralização }\end{array}$ & $\begin{array}{l}\text { Greiner } \\
(1972)\end{array}$ & Alto & Médio & $\begin{array}{c}\text { Médio; Dividido com } \\
\text { outros gerentes }\end{array}$ \\
\hline & Centralização & $\begin{array}{l}\text { Hanks et } \\
\text { al. (1993) }\end{array}$ & $\begin{array}{l}\text { Alta, baseada no } \\
\text { fundador }\end{array}$ & Delegação limitada & Moderada \\
\hline \multirow{4}{*}{ 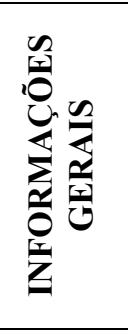 } & $\begin{array}{l}\text { Sistemas de } \\
\text { controles }\end{array}$ & $\begin{array}{l}\text { Greiner } \\
(\mathbf{1 9 7 2}) \\
\end{array}$ & $\begin{array}{c}\text { Resultados de } \\
\text { mercado }\end{array}$ & $\begin{array}{l}\text { Padronizados e } \\
\text { centros de custos }\end{array}$ & $\begin{array}{c}\text { Relatórios e centros de } \\
\text { lucratividade }\end{array}$ \\
\hline & Pessoas & $\begin{array}{c}\text { Galbraith } \\
\text { (1982) }\end{array}$ & $\begin{array}{c}\text { Faz tudo; } \\
\text { corredor de risco }\end{array}$ & $\begin{array}{c}\text { Especialistas } \\
\text { funcionais } \\
\end{array}$ & $\begin{array}{c}\text { Pessoas de negócios; } \\
\text { planejadores }\end{array}$ \\
\hline & $\begin{array}{l}\text { Geração de } \\
\text { fluxo de caixa }\end{array}$ & \multirow{2}{*}{$\begin{array}{l}\text { Scott e } \\
\text { Bruce } \\
(1987)\end{array}$} & Negativo & Ponto de equilíbrio & Positivo \\
\hline & $\begin{array}{l}\text { Sistema e } \\
\text { controles }\end{array}$ & & Simples e visual & Simples e pessoal & $\begin{array}{c}\text { Sistemas de controles } \\
\text { simples }\end{array}$ \\
\hline
\end{tabular}

Fonte: Elaborado pelos autores (2009).

As categorias de variáveis, incluídas no grupo dois, procuraram delinear o tipo de estrutura apresentado pelas empresas nos estágios. Greiner (1972) nomeou como estrutura organizacional. Galbraith (1982) como estrutura. A terminologia de Churchill e Lewis (1983) destoa das demais; apesar da clara intenção dos autores de tratar das configurações das empresas, eles nomearam como organização, enquanto que Scott e Bruce (1987), Lester et al. (2003), também como estrutura. O terceiro grupo é composto das categorias relacionadas ao tipo de descentralização do poder no processo de tomada de decisão. Envolve a narrativa de Greiner (1972) sobre o tipo de descentralização ou grau de centralização e a centralização de Hanks et al. (1993).

O quarto grupo inclui as categorias de variáveis genéricas; por isso, recebeu o nome de informações gerais. Constam dele o sistema de controle de Greiner (1972), de pessoas de Galbraith (1982), e os sistemas e de controles e de geração de fluxo de caixa de Scott e Bruce (1987).

Quanto à formalização dos processos, no primeiro estágio ela é mínima e flexível ou até não existente (HANKS et. al., 1993; GREINER, 1972). No estágio dois, são implantados alguns sistemas formais, como o orçamento. Mas de forma embrionária, pois a maior preocupação da empresa, ainda, é sobre os aspectos externos (GALBRAITH, 1982; HANKS et al., 1993). A implantação dos sistemas alcança um alto nível de formalização no terceiro estágio (HANKS et al., 1993). Para Galbraith (1982), a empresa já dispõe de sistemas de controles, planejamento, orçamento e de informações. Porém, Churchill e Lewis (1983) consideraram a formalização nesse estágio como básica.

A estrutura organizacional no primeiro estágio é informal, simples e desestruturada (GREINER, 1972; CHURCHILL; LEWIS, 1983; SCOTT; BRUCE, 1987). No segundo estágio, predomina o tipo de estrutura funcional (GALBRAITH, 1982; CHURCHILL; LEWIS, 1983). No terceiro, as definições dos tipos de estrutura utilizadas pelos autores divergem. Lester et al. (2003) 
denominaram de divisional, formal e burocrática; Hanks et al. (1993), de divisional; porém, os demais autores citam que a estrutura mantém ainda o design funcional. Galbraith (1982) e Scott e Bruce (1987) também classificam como funcional, mas com ligações entre os níveis e divisão do trabalho. O modelo divisional apregoado por Lester et al. (2003) para o estágio três, raramente se aplica às pequenas empresas. Pois, segundo Mintzberg (1985), essa forma é acoplada por divisões, que possuem estruturas próprias, com demanda de grande número de funcionários.

A tomada de decisão no estágio um é centralizada no dirigente (GREINER, 1972; HANKS et al., 1993). No segundo estágio, com a contratação de novos administradores, o proprietário delega algumas atribuições e decisões, mas de forma limitada (HANKS et al., 1993). No estágio três, o grau de descentralização é moderado, mas mantém uma sintonia com o tipo de estrutura, geralmente funcional. Neste estágio, o dirigente delega poder aos administradores contratados para tomada de decisões operacionais, porém centraliza as decisões sobre assuntos importantes (GREINER, 1972; HANKS et al., 1993).

Quanto às variáveis de informações gerais, no primeiro estágio os sistemas de controles são voltados ao mercado e o acompanhamento é visual. Não existe uma clara divisão do trabalho as pessoas fazem tudo e o fluxo de caixa é negativo (GALBRAITH, 1982; SCOTT; BRUCE, 1987). No estágio dois, os sistemas de controles passam a ser mais padronizados, e a empresa provavelmente alcança o ponto de equilíbrio econômico-financeiro. No terceiro estágio, a empresa já consegue gerar fluxo de caixa positivo e os seus sistemas de controles passam a ser exercidos por meio de relatórios gerenciais (GREINER, 1972; SCOTT; BRUCE, 1987).

\subsection{Estratégia}

No primeiro estágio, a empresa procura desenvolver, fazer e testar um novo produto, vendê-lo ou prestar os primeiros serviços. A estratégia principal é da existência, que é assegurar o nascimento da empresa e criar mercado. Essa opção estratégica pode ser compatível com a estratégia prospectora de Miles e Snow (1978) e com a de ser a primeira empresa a se mover, em nichos inovadores e pouco explorados, conforme apresentado no quadro 5 (GREINER, 1972; MILES; SNOW, 1978; GALBRAITH, 1982; CHURCHILL; LEWIS, 1983; SCOTT; BRUCE, 1987; LESTER et al., 2003).

Quadro 5 - Descrição das categorias da dimensão estratégia

\begin{tabular}{|c|l|c|c|c|}
\hline \multicolumn{5}{|c|}{ ESTRATÉGIA } \\
\hline Autor & Critérios & Estágio 1 & Estágio 2 & Estágio 3 \\
\hline Greiner (1972) & $\begin{array}{l}\text { Foco } \\
\text { Gerencial }\end{array}$ & Fazer e vender & Eficiência operacional & Expansão de mercado \\
\hline Galbraith (1982) & Tarefas & Inventar, fazer e testar & Fazer e distribuir & Fazer e ser lucrável \\
\hline
\end{tabular}




\begin{tabular}{|c|l|c|c|c|}
\hline $\begin{array}{c}\text { Churchill e Lewis } \\
(1983)\end{array}$ & $\begin{array}{l}\text { Estratégia } \\
\text { Principal }\end{array}$ & Existir & Sobreviver & $\begin{array}{c}\text { Manter a lucratividade } \\
\text { - } \text { status quo (SD) }^{1}\end{array}$ \\
\hline Scott e Bruce 1987) & $\begin{array}{l}\text { Assuntos- } \\
\text { Chave }\end{array}$ & Obter Clientes & Renovação e dispêndio & $\begin{array}{c}\text { Gerenciar crescimento } \\
\text { /Assegurar recursos }\end{array}$ \\
\hline Lester et al. (2003) & Estratégia & $\begin{array}{c}\text { Prospectora. } \\
\text { Primeiro a se mover }\end{array}$ & $\begin{array}{c}\text { Analítica. } \\
\text { Segundo a se mover }\end{array}$ & $\begin{array}{c}\text { Defensora. } \\
\text { Controle de um } \\
\text { segmento de mercado }\end{array}$ \\
\hline
\end{tabular}

Fonte: Elaborado pelos autores (2009).

O segundo estágio é caracterizado pela expansão do mercado, pelo possível crescimento da empresa e pela busca de eficiência operacional. Nesse estágio, a estratégia da empresa é garantir a sobrevivência (GREINER, 1972; GALBRAITH, 1982; CHURCHILL; LEWIS, 1983; SCOTT; BRUCE, 1987; LESTER et al., 2003).

Churchill e Lewis (1983) separaram o terceiro estágio, sucesso, em dois subestágios, com opções estratégias diferentes. No primeiro, sucesso desimpedido, a estratégia principal da empresa é manter a lucratividade, o status quo, enquanto que no segundo - sucesso-crescimento - a intenção da empresa é obter recursos para impulsionar o seu crescimento continuado. O subestágio — sucesso desimpedido - é o que mantém maior sintonia com os demais autores, por isso, ele foi priorizado nesta descrição, em vez do estágio de sucesso de crescimento.

No terceiro estágio, provavelmente, tanto o mercado como a empresa encontram-se em ritmo de expansão. Assim, a intenção estratégica do dirigente é tornar a empresa lucrativa (GREINER, 1972; GALBRAITH, 1982; SCOTT; BRUCE, 1987). Apesar de essa proposição abranger empresas de vários setores, ela é mais direcionada para as empresas tecnológicas, nas quais o período de maturação do investimento e o de geração de lucro são mais lentos do que no varejo ou na indústria tradicional. Somente a partir do terceiro estágio, é que a lucratividade é alcançada por essas empresas, possibilitando assim, que elas recuperem os investimentos (GALBRAITH, 1982). A estratégia principal do estágio é manter a situação de crescimento, assim como o assunto-chave é gerenciá-lo. A ênfase muda de um foco externo para um interno, a fim de estruturar a organização para sustentar e manter o controle do crescimento pretendido (GREINER, 1972; SCOTT; BRUCE, 1987).

\subsection{Contexto Organizacional}

As categorias de contexto no primeiro estágio corroboram a noção de que a empresa é jovem e pequena. A extensão da linha de produto ou serviço é estreita, e a sua base de desenvolvimento

\footnotetext{
${ }^{1} \mathrm{SD}$ e SC referem-se aos subestágios Sucesso-Desimpedido e Sucesso-Crescimento.
} 
são as ações empreendedoras do dirigente, conforme apresentado no quadro 6 (GREINER, 1972; CHURCHILL; LEWIS, 1983; SCOTT; BRUCE, 1987; LESTER et al., 2003). A taxa de crescimento nesse período é inconsistente, e os investimentos são destinados ao aprimoramento da planta e à compra de equipamentos ou ao aperfeiçoamento das condições de prestação de serviços (HANKS et al., 1993). O segundo estágio é caracterizado pela possível contratação de um administrador profissional. A principal tarefa dele é melhorar o produto ou serviço e o sistema de distribuição. Neste estágio, aumenta a importância das questões financeiras, uma vez que a empresa necessita gerar fluxo de caixa para sustentar o seu crescimento e incrementar o capital de giro (GREINER, 1972; GALBRAITH, 1982; CHURCHILL; LEWIS, 1983; SCOTT; BRUCE, 1987; LESTER et al., 2003). No terceiro estágio, a preocupação da empresa é com a ampliação da produção e com a coordenação da rede de distribuição.

Quadro 6 - Descrição das categorias da dimensão contexto

\begin{tabular}{|c|c|c|c|c|}
\hline \multicolumn{5}{|c|}{ CONTEXTO ORGANIZACIONAL } \\
\hline Autor & Categoria & Estágio 1 & Estágio 2 & Estágio 3 \\
\hline \multirow[b]{2}{*}{ Greiner (1972) } & Ênfase & $\begin{array}{c}\text { Criação de um } \\
\text { produto e mercado }\end{array}$ & Contratar um gerente & Estruturar a empresa \\
\hline & Crescimento por & Empreendedorismo & Eficiência & $\begin{array}{c}\text { Motivação dos } \\
\text { gerentes }\end{array}$ \\
\hline & $\begin{array}{l}\text { Principais } \\
\text { investimentos }\end{array}$ & $\begin{array}{c}\text { Planta e } \\
\text { equipamentos }\end{array}$ & Capital de giro & Extensão da planta \\
\hline $\begin{array}{l}\text { Scott e Bruce } \\
\quad(1987)\end{array}$ & $\begin{array}{l}\text { Linha de } \\
\text { produto/mercado }\end{array}$ & $\begin{array}{c}\text { Simples e distribuição } \\
\text { limitada }\end{array}$ & $\begin{array}{l}\text { Simples e mercado } \\
\text { em crescimento }\end{array}$ & $\begin{array}{l}\text { Em expansão, } \\
\text { mercado simples e } \\
\text { crescimento da } \\
\text { distribuição }\end{array}$ \\
\hline Hanks et al. (1993) & $\begin{array}{l}\text { Taxa de } \\
\text { crescimento }\end{array}$ & Inconsistente & Positivo rápido & Lento \\
\hline Lester et al. (2003) & Situação & Jovem e pequena & Média & Grande \\
\hline
\end{tabular}

Fonte: Elaborado pelos autores (2009).

Embora os modelos de ciclo de vida estudados definam de modo diferente as mudanças organizacionais, esta seção apresentou uma proposta de agrupamento dos vários padrões de mudanças organizacionais em quatro dimensões. A seção seguinte discute como categorizar esses padrões em três estágios, de forma que possa facilitar a operacionalização do ciclo de vida na pequena empresa.

\section{Discussões e resultados}

Como resultado, apresenta-se uma discussão sobre as implicações dos levantamentos promovidos na seção anterior e uma caracterização dos estágios, a fim de se estabelecer uma categorização de ciclo de vida organizacional direcionada à pequena empresa do setor metalmecânico. 
Como ponto inicial de discussão, observa-se que as dimensões estratégia e contexto organizacional foram pouco explorados nos estudos sobre o ciclo de vida, prevalecendo as definições associadas à dimensão organização, como estrutura e sistemas de controles (MILLER; FRIESEN, 1984; LESTER; PARNELL, 2002). Entende-se que essa carência é um acontecimento natural, uma vez que, os estudos priorizaram os fatores internos das organizações e os de fácil constatação.

Assim, apresentam-se algumas sugestões para diminuir essas limitações. Para a dimensão contexto organizacional, Miller e Friesen (1984) sugeriram as variáveis tamanho absoluto da empresa, heterogeneidade do ambiente, hostilidade dos competidores e influência dos clientes. $\mathrm{O}$ tamanho refere-se à representatividade da empresa em face dos demais concorrentes. Heterogeneidade do ambiente refere-se principalmente à quantidade de linhas de produtos, aos canais de distribuição e às táticas competitivas da empresa quando comparadas aos demais concorrentes. A variável, competidores trata do grau de hostilidade deles com a empresa, e clientes refere-se à influência dos compradores nos direcionamento das ações da empresa (LESTER; PARNELL, 2002). Essas variáveis, embora direcionadas às grandes empresas, mostram-se, quando ajustadas, pertinentes às pequenas. Para isso, exige-se apenas a definição de conteúdos específicos, conforme os seus padrões de transformações organizacionais nos estágios das pequenas empresas.

Quanto à pequena quantidade de categorias da dimensão estratégia, ocorreu porque os estudiosos do ciclo de vida concentram-se nos aspectos mais tangíveis da estratégia. Por isso, eles optaram pelo registro das orientações estratégicas adotadas pelas empresas em determinados estágios e pela comparação superficial dos tipos de estratégia, por meio de breves menções a Miles e Snow (1978). Assim, este ainda é um assunto descoberto. Situação que pode ser amenizada com a inclusão de categorias de análises relacionadas às transformações dos processos estratégicos ao longo dos períodos de desenvolvimento da pequena empresa. Como nas características do processo de formulação estratégica, do contínuo totalmente deliberado ao totalmente emergente e na averiguação dos aspectos de formalização e de implementação da estratégia entre outros.

Agora, examinando-se a categorização do ciclo de vida organizacional direcionada à pequena empresa do setor metal-mecânico, esclarece-se que a definição dos nomes dos estágios se deu a partir da apreciação da síntese do quadro 1 e das nomenclaturas constantes no quadro 2. O primeiro estágio foi denominado como Estabelecimento, porque neste período as pequenas empresas dedicam esforços para se estabelecerem no mercado e para delimitarem o seu espaço de atuação. $\mathrm{O}$ segundo, como Direção, porque depois de superado o primeiro período, a empresa precisa de um modelo de gestão e de definir o caminho que deseja seguir. Por isso, ela decidirá também sobre os meios necessários para amparar esse desejo. O terceiro estágio foi denominado como Consolidação, 
pois, neste período, a empresa precisa se preparar para as novas demandas, oriundas da sua nova condição e das ações dos concorrentes.

Quadro 7 - Descrição do Estágio 1

\begin{tabular}{|c|c|c|c|}
\hline \multicolumn{4}{|c|}{ ESTABELECIMENTO } \\
\hline $\begin{array}{c}\text { Dirigente } \\
\text { Alto grau de envolvimento } \\
\text { direto nas atividade } \\
\text { operacionais }\end{array}$ & $\begin{array}{c}\text { Organização } \\
\text { Estratégia }\end{array}$ & Contexto \\
\hline $\begin{array}{c}\text { Centraliza as decisões } \\
\text { importantes }\end{array}$ & $\begin{array}{c}\text { Não existe sistema de } \\
\text { comunicação estabelecido }\end{array}$ & $\begin{array}{c}\text { O Assunto principal é criar } \\
\text { mercado }\end{array}$ & $\begin{array}{c}\text { Monitoramento ambiente } \\
\text { A principal preocupação é } \\
\text { dobter clientes } \\
\text { clientes. }\end{array}$ \\
\hline $\begin{array}{c}\text { Supervivo. } \\
\text { as atividadides, uso } \\
\text { principalmente da } \\
\text { comunicação verbal }\end{array}$ & $\begin{array}{c}\text { Estrutura simples com um } \\
\text { nível hierárquico ou } \\
\text { nenhum }\end{array}$ & $\begin{array}{c}\text { As pretensões futuras são } \\
\text { baseadas principalmente na } \\
\text { visão pessoal do dirigente; } \\
\text { para o curto prazo, período } \\
\text { de até um ano. }\end{array}$ & $\begin{array}{c}\text { Alta dependência de } \\
\text { fornecedores }\end{array}$ \\
\hline
\end{tabular}

Fonte: Elaborado pelos autores (2009).

As pequenas empresas que se enquadram no estágio 1 caracterizam-se pelo alto grau de dependência do dirigente, baixo grau de formalização nos processos e controles, estratégia simples e única e alto grau de dependência e vulnerabilidade do seu contexto, conforme apresentado no quadro 7.

Quadro 8 - Descrição do Estágio 2

\begin{tabular}{|c|c|c|c|}
\hline \multicolumn{5}{|c|}{ DIREÇÃO } \\
\hline Dirigente & Organização & Estratégia & Contexto \\
\hline $\begin{array}{c}\text { Envolvimento moderado } \\
\text { nas atividades operacionais }\end{array}$ & $\begin{array}{c}\text { São estabelecidas algumas } \\
\text { normas e regras escritas }\end{array}$ & $\begin{array}{c}\text { A preocupação é com a } \\
\text { organização interna da } \\
\text { empresa e com as ações } \\
\text { dos concorrentes }\end{array}$ & $\begin{array}{c}\text { Moderado grau de } \\
\text { retaliação dos concorrentes }\end{array}$ \\
\hline $\begin{array}{c}\text { Descentraliza a tomada de } \\
\text { algumas decisões } \\
\begin{array}{c}\text { importantes, mas toma a } \\
\text { maioria das decisões }\end{array}\end{array}$ & $\begin{array}{c}\text { É estabelecido um sistema } \\
\text { de comunicação, embora } \\
\text { ainda simples }\end{array}$ & $\begin{array}{c}\text { Buscar a viabilidade do } \\
\text { empreendimento }\end{array}$ & Realiza algum \\
\hline $\begin{array}{c}\text { Supervisiona direta e } \\
\text { indiretamente as atividades, } \\
\text { uso de comunicação verbal } \\
\text { e eventualmente escrita }\end{array}$ & $\begin{array}{c}\text { Estrutura ainda simples, } \\
\text { com dois níveis } \\
\text { hierárquicos }\end{array}$ & $\begin{array}{c}\text { O dirigente é o responsável } \\
\text { pela definição do futuro da } \\
\text { empresa, mas ele envolve } \\
\text { alguns funcionários; para o } \\
\text { médio prazo, até dois anos }\end{array}$ & $\begin{array}{c}\text { Moderada dependência dos } \\
\text { fornecedores }\end{array}$ \\
\hline
\end{tabular}

Fonte: Elaborado pelos autores (2009).

Já as pequenas empresas condizentes com o estágio 2 caracterizam-se pela implantação de um modelo de gestão mais profissional e pela preocupação com a estruturação do empreendimento. Elas diferenciam-se das empresas do estágio 1, pela manifestação da formalização dos seus processos e controles e pela separação da função de direção das operações rotineiras; existem, na sua estrutura organizacional, até dois níveis hierárquicos, conforme apresentado no quadro 8. 
No estágio 3, as pequenas empresas caracterizam-se pela consolidação dos seus processos e controles, pela distribuição do poder do dirigente com outras funções gerenciais, pelo estabelecimento de uma estrutura organizacional mais aprimorada, geralmente funcional e pela crescente preocupação com os efeitos dos fatores do contexto na vida da empresa, conforme retratado no quadro 9.

Quadro 9 - Descrição do Estágio 3

\begin{tabular}{|c|c|c|c|}
\hline \multicolumn{4}{|c|}{ CONSOLIDAÇÃO } \\
\hline Dirigente & Organização & Estratégia & Contexto \\
\hline $\begin{array}{c}\text { Envolvimento com as } \\
\text { atividades gerenciais e } \\
\text { estratégicas }\end{array}$ & $\begin{array}{c}\text { São estabelecidos vários } \\
\text { conjuntos de normas e } \\
\text { regras escritas }\end{array}$ & $\begin{array}{c}\text { Ampliar a linha de } \\
\text { produtos }\end{array}$ & $\begin{array}{c}\text { Alto o grau de retaliação } \\
\text { dos concorrentes }\end{array}$ \\
\hline $\begin{array}{c}\text { Concentra-se em poucas } \\
\text { decisões importantes, pois } \\
\text { delega a maioria das } \\
\text { decisões }\end{array}$ & $\begin{array}{c}\text { O sistema de comunicação } \\
\text { é composto de vários meios } \\
\text { e de uso freqüentes }\end{array}$ & $\begin{array}{c}\text { Aumentar a lucratividade e } \\
\text { pensar em crescer }\end{array}$ & $\begin{array}{c}\text { Acompanha os eventos do } \\
\text { ambientes e toma algumas } \\
\text { medidas preventivas }\end{array}$ \\
\hline $\begin{array}{c}\text { Supervisão indireta, uso de } \\
\text { orientações escrita }\end{array}$ & $\begin{array}{c}\text { Consolidação de uma } \\
\text { estrutura funcional ou } \\
\text { divisional e com mais de } \\
\text { três níveis }\end{array}$ & $\begin{array}{c}\text { O dirigente define apenas } \\
\text { os alvos principais e alguns } \\
\text { funcionários definem os } \\
\text { demais pontos; para o } \\
\text { médio-longo prazo, mais } \\
\text { de três anos }\end{array}$ & $\begin{array}{c}\text { Baixa dependência dos } \\
\text { fornecedores }\end{array}$ \\
\hline
\end{tabular}

Fonte: Elaborado pelos autores (2009).

Em suma, procurou-se, pela descrição apresentada, disponibilizar uma fonte de classificação das pequenas empresas em um dos três estágios. Ressalta-se que, embora se estabelecessem fronteiras entre os estágios, é possível que, nos trabalhos empíricos, as empresas pequenas apresentem características combinadas, ou seja, pertencentes a mais de um estágio. Isso, ao invés de ser um obstáculo, é um acontecimento esperado, pois, como metáfora, o ciclo de vida organizacional, capta parcialmente a realidade, e também porque o desenvolvimento das dimensões pode não seguir um ritmo simétrico. Assim, espera-se que os trabalhos empíricos produzam mais detalhes, aperfeiçoando o modelo com a inclusão de novos estágios ou com o desdobramento dos atuais, contribuindo significativamente com a teoria do ciclo de vida na pequena empresa.

\section{Conclusões}

Considerando que a discussão de temas sobre a sistematização do ciclo de vida organizacional trará benefícios para as pesquisas da pequena empresa, este trabalho procurou demonstrar a possibilidade de se relacionar as quatro dimensões das especificidades de gestão da pequena empresa com três estágios do ciclo de vida organizacional. Como resultado, elaborou-se uma classificação, que pode facilitar a categorização do estágio organizacional da pequena empresa do setor metal-mecânico. 
A categorização sugerida não é irreajustável; pelo contrário, ela pode sofrer alterações e adequações conforme o interesse do pesquisado, pois sabe-se que o caminho a ser trilhado para construção de uma categorização definitiva ainda é longo. No entanto, acredita-se que esse pequeno passo diminui essa distância e estimula o uso do ciclo de vida organizacional como variável interveniente nas pesquisas sobre pequena empresa.

Este é um trabalho teórico, é um esforço para contribuir na definição das especificidades da pequena empresa e na operacionalização do ciclo de vida organizacional. Assim, recebe críticas e possui limitações como todo trabalho teórico. Além disso, a categorização proposta é voltada para as pequenas empresas do setor metal-mecânico. Porém, isso não a impede de ser ajustada e aplicada em empresas de outros setores.

\section{Abstract}

The purpose of this work is to present a set of specific management of small business in four dimensions: Manager, Organization, Strategy and Organizational Context and from those dimensions, propose a categorization of organizational life cycle. The categorization has been developed from work on the international literature. As a result, it made a number of categories, to facilitate the identification of the organizational stage of the small business sector of the metalmechanic.

Key-words: small business. organizational life cycle.

\section{Referências}

ADIZES, I. (1996). Os ciclos de vida das organizações. São Paulo: Pioneira.

CHURCHILL, N. C.; LEWIS, V. L. (1983). Growing Concerns - Topics of particular interest to owners and managers of smaller businesses. Harvard Business Review, Watertown, may-jun., p.30-50.

COOPER, A. C. (1979). Strategy management: new venture and small business. In.: SCHENDEL, D. E.; HOFER, C. W. (ed.). Strategic Management. Boston: Little, Brown and company, p. 316-327.

D'AMBOISE, G.; MULDOWNEY, M. (1988) Management Theory for Small Business: attempts and requirements. The Academy of Management Review, New York, v. 13, n. 2, apr.

DANDRIDGE, T. C. (1979). Children are not "little grown-ups": small business needs its own organizational theory. Journal of Small Business Management, Florida, v. 17, n 2, p. 53-57, apr. 1979.

DODGE. R. H.; FULLERTON, S.; ROBBINS, J. E. (1994). Stage of the organizational life cycle and competition as mediators of problem perception for small business. Strategic Management Journal, Hoboken, v. 15, n. 2; p-121-135, feb.

DRUCKER, P. F. (1981). A prática de administração de empresas. São Paulo: Pioneira.

ESCRIVÃO FILHO, E. (2006) Pequena empresa e administração estratégica: reconhecendo especificidades, restrições e facilitadores com o mapa organizacional. Tese ( Livre Docência). Escola de Engenharia de São Carlos. Universidade de São Paulo, São Carlos, 2006.

ESCRIVÃO FILHO, E.; CARVAlHO, K. C.; BENZE, R. P.; ALBUQUERQUE, A. F. (2005). Compreendendo a dinâmica das pequenas empresas: mapa organizacional como ferramenta da ação administrativa. Revista de Ciências Humanas e Aplicadas (Matiz), Matão: Instituto Matonense Municipal de Ensino Superior - INMES, n. 1. p. 20-40. 
GALBRAITH, J. (1982). The stages of growth. Journal of Business Strategy, Englewood, v. 3, n. 1, p.70-79, summer. cross ${ }^{\text {ref }}$

GARTNER, W.B. (1985). A conceptual framework for describing the phenomenon of new venture creation. Academy of Management Review, v. 10, n. 4 , p. 696-706.

cross ${ }^{\text {ref }}$

GREINER, L. E. (1972). Evolution and revolution as organizations grow. Harvard Business Review, Watertown, v. 50 , n. 4 , p. $37-46$, jul-aug.

GREINER, L. E. (1998). Evolution and revolution as organizations grow. Harvard Business Review, Watertown, v. 76, n. 3, p. 55-68, may-jun.

GUPTA, Y. P.; CHIN, D. C. W. (1994). Organizational life cycle: a review and proposed directions for research. The Mid-Athantic Journal of Business, v. 30, n. 3, p. 269-294, dec.

HALL, R. H. (1984). Organizações: estrutura e processos. Rio de Janeiro: Prentice-Hall do Brasil.

HANKS, S. H. ; WATSON, C. J. ; JANSEN, E. ; CHANDLER, G. N. (1993). Tightening the lifecycle construct: a taxonomic study of growth stage configurations in high-technology organizations. Entrepreneurship: Theory and Practice, Waco, v.18, n. 2, p. 5-25, winter.

JULIEN, P. (1997). Théorie économique des PME. In: JULIEN, P. Lês PME bilan et perspectives. Québec: Economica.

KIMBERLY, J. R.; MILES, R. H. (1980). The Organizational Life Cycle: Issues in the Creation, Transformation, and Decline of Organizations. San Francisco, California: Jossey - Bass Publishers.

LEONE, N. M. C. P. G. (1999). As especificidades das pequenas e médias empresas. Revista de Administração, São Paulo: FEA/USP, v. 34, n. 2, p.91-94, abr/jun.

LEONE, N.M.C.O.G. (1991). A dimensão física das pequenas e médias empresas (P.M.E’S): À procura de um critério homogeneizador, Revista de Administração de Empresas, v. 31, n.2, abr/jun, p. 53-59.

LESTER, D. L.; PARNELL, J. A. (2002). Aligning factors for successful organizational renewal. Leadership \& Organization Development Journal, v. 23, n. 1, p. 60-67.

crossef

LESTER, D. L.; PARNELL, J. A.; CARRAHER, S. (2003). Organizational life cycle: a five-stage empirical scale. International Journal of Organizational Analysis, Bingley, v. 11, n. 4, p. 339-354.

MACHADO-DA-SILVA, C. L.; VIEIRA, M. M. F.; DELlAGNELL, E. H. L. (1998). Ciclo de vida, controle e tecnologia: um modelo para análise das organizações. Organização \& Sociedade, v. 5, n. 11, jan./abr.

MILLER, D.; FRIESEN, P. H. (1984). A Longitudinal Study of the Corporate Life Cycle. Management Science, v. 30 , n. 10, p. 1161-1183, oct.

cross ${ }^{\text {ref }}$

NADLER, D. A.; GERSTEIN, M. S.; SHAW, R. B. (1994). Arquitetura organizacional: a chave para a mudança empresarial. Rio de Janeiro: Campus.

OLIVEIRA, J., SILVA, J. T. Verticidade no ciclo de vida das Pequenas Empresas In: XV SIMPEP - Simpósio de Engenharia de Produção, 2007, Bauru. XV SIMPEP - SIMPÓSIO DE ENGENHARIA DE PRODUÇÃO. BauruSP: UNESP, 2007. v.1. p.1 - 1

O'RAND, A. M.; KRECKER, M. L. (1990). Concepts of the life cycle: their history, meaning, and uses in the social sciences. Annual Review Social, v. 16, p. 241-262. 
QUINN, R. E.; CAMERON, K. (1983). Organizational life cycles and shifting criteria of effectiveness: some preliminary evidence. Management Science, v. 29, n 1, p. 33-51, jan.

cross ${ }^{\text {ref }}$

RATTNER, H. (coord.) (1985) Pequena empresa: o comportamento empresarial na acumulação e na luta pela sobrevivência. São Paulo: Brasiliense.

RAMOS, F. (1995). A grande dimensão da pequena empresa: perspectivas de ação. Brasília: SEBRAE.

ROBINSON Jr., R.; PEARCE II, J. A.; VOZIKIS, G. S. MESCON, T. S. (1984). The relationship between stage of development and small firm planning and performance. Journal os Small Business Management, v. 22, n. 2, p. 45-52, apr.

SCHEIN, E. H. (1980). Problemas humanos nas organizações. In:_. Psicologia Organizacional. Rio de Janeiro: Prentice-Hall, p. 10-28.

SCOTT, M.; BRUCE, R. (1987). Five Stages of Growth in Small Business. Long Range Planning, London, v.20, n. 3 ; p. 45-53, jun.

cross ${ }^{\text {ref }}$

SBA (2008). Table os Small Business Size Standards. Disponível em: <http://www.sba.gov/size>. Acesso em: 17 de janeiro 2009.

SEBRAE. (2006). Onde estão as micro e pequenas empresas no Brasil. Estudo realizado pelo SEBRAE-SP.

TERENCE, A. C. F. (2008). Processo de criação de estratégias em pequenas empresas: elaboração de um mapa estratégico para empresas de base tecnológica do pólo de São Carlos/SP. Tese (Doutorado em Engenharia de Produção). Escola de Engenharia de São Carlos, Universidade de São Paulo, São Carlos, 2008.

TORRÈS, O.; JULIEN, P.A. Specificity and denaturing of small business. International Small Business Journal, v. 23 , n. 4 , p. $355-377,2005$.

cross ${ }^{\text {ref }}$

\section{Dados dos autores:}

Nome completo: Jair de Oliveira

Filiação institucional: Universidade Tecnológica do Paraná - Cornélio Procópio

Departamento: COEME

Função ou cargo ocupado: Professor

Endereço completo para correspondência (bairro, cidade, estado, país e CEP): Rua Jesuíno de Arruda, 1365. Centro - São Carlos - SP - 13.560-642

Telefones para contato: 16 - 34127485

e-mail:jair37@gmail.com

Nome completo: Edmundo Escrivão Filho

Filiação institucional: Escola de Engenharia de São Carlos - USP

Departamento: SEP - Engenharia de Produção

Função ou cargo ocupado: Professor Associado

Endereço completo para correspondência (bairro, cidade, estado, país e CEP): Av. Trabalhador Sãocarlense, 400, Parque Arnold Schimidt. São Carlos-SP - Brasil - 13566-590

Telefones para contato: (16) 3373-9428

e-mail: edesfi@sc.usp.br

Recebido para publicação em: 27/01/2009

Aceito para publicação em: 13/03/2009 